\title{
Efeito de secas prolongadas nos recursos hídricos de uma região semiárida: uma análise comparativa para o Ceará
}

\section{Extended drought effects in semi-arid water resources: a comparative analysis for Ceara state}

Data de entrada: $19 / 05 / 2017$

Data de aprovação: 21/09/2017

\section{Resumo}

Este trabalho apresenta uma metodologia de análise simplificada para avaliação dos efeitos da seca prolongada ocorrida entre os anos de 2012 e 2016 em uma região semiárida, mais especificamente no Estado do Ceará, a partir de dados fornecidos pela Companhia de Gestão dos Recursos Hídricos do Estado (COGERH) e pela Fundação Cearense de Meteorologia e Recursos Hídricos (FUNCEME). O estudo avaliou os impactos apresentados para o Estado em três pontos principais: no regime de precipitações durante a quadra chuvosa; nos reservatórios de regularização; na diminuição da oferta hídrica para irrigação e para consumo populacional. Procedeu-se também uma breve comparação entre o reservatório equivalente do Ceará e de outros Estados da região Nordeste no período, a partir de dados apresentados pela Agência Nacional de Águas (ANA), assim como uma comparação entre a evolução do percentual de acúmulo entre 2012 e 2016 do Açude Castanhão - CE e do Sistema Canteira - SP, que também sofreu os efeitos de uma crise hídrica no período entre 2014 e 2015. Os resultados mostraram que as precipitações totais das quadras chuvosas cearenses estiveram todas abaixo da média histórica no período, com destaque para o ano de 2012, com -50,7 \% de diferença. Os anos de 2012, 2013 e 2016 estão entre os dez piores anos em termos de precipitação no Estado. A média de aporte dos reservatórios no período foi de 0,91 bilhões de $\mathrm{m}^{3} / \mathrm{ano}$, com uma redução de $78,25 \%$ nos volumes acumulados nesses açudes entre 2012 e 2016 . Os perímetros irrigados apresentaram queda de $84,4 \%$ na vazão ofertada, enquanto 74,4\% dos municípios do Estado decretaram estado de emergência devido à seca ao final de 2016. Em termos de região Nordeste, Ceará, Paraíba, Pernambuco e Rio Grande do Norte foram os Estados em que os reservatórios mais sofreram os impactos da seca, enquanto Bahia e Piauí foram menos afetados. Na comparação Castanhão $x$ Cantareira, mesmo com as causas e durações das secas sendo diferentes, os dois açudes atingiram níveis abaixo do mínimo operacional, chegando o Cantareira até mesmo a utilizar as reservas técnicas para abastecimento. Combinando-se os resultados do presente estudo com trabalhos anteriores sobre a seca, pode-se atestar que as mudanças climáticas não têm criado secas mais severas em termos de precipitações. Mesmo assim, situações de secas extremas e de secas prolongadas continuam a impactar de forma preocupante as populações. Por fim, a análise realizada pode servir como ferramenta preliminar para avaliação dos impactos de secas prolongadas no semiárido, possibilitando ações mais eficientes no gerenciamento dos recursos hídricos.

Palavras-chave: Seca prolongada. Semiárido. Recursos hídricos.

Udinart Prata Rabelo - Engenheiro Civil (UFC). Mestrando em Recursos Hídricos (DEHA/UFC).

Iran E. Lima Neto - Engenheiro Civil (UFC). Mestre em Hidráulica e Saneamento (EESC/USP). PhD em Engenharia Hidráulica (Universidade de Alberta/Canadá). Professor Adjunto (DEHA/UFC).

"Endereço para correspondência: Departamento de Engenharia Hidráulica e Ambiental/UFC - Campus do Pici - Bloco $713,1^{\circ}$ andar - CEP: 60451-970 - Fortaleza (CE), Brasil. E-mail: iranadeha.ufc.br 


\section{Abstract}

This paper presents a simplified methodology to evaluate the effects of the extended drought that occurred between 2012 and 2016 in a semi-arid region in Ceara state, based on data provided by the Water Resources Management Company and the Meteorology and Water Resources Ceara Foundation. The study evaluated the impacts considering three main points: the rainfall regime during rainy season; the regularization reservoirs; the reduction of water supply for irrigation and popular consumption. A comparison was also made between the equivalent reservoir of Northeast states in the period, based on data presented by National Water Agency, as well as a comparison between the evolution of the accumulation percentage of Castanhão Reservoir - CE and Cantareira System - SP, which also suffered the effects of a water crisis in the period 20142015. The results showed that rainfall during rainy season was always below the historical average in the period, with highlight for 2012, with a -50.7\% difference. The years of 2012, 2013 and 2016 are among the ten worst in terms of rainfall in the state. The average contribution of the reservoirs in the period was 0.91 billion $\mathrm{m}^{3} / \mathrm{year}$, with a reduction of $78.25 \%$ in the accumulated volumes in these reservoirs between 2012 and 2016. The irrigated perimeters showed an $84.4 \%$ drop in the offered flow, while $74.4 \%$ of the cities decreed a state of emergency due to drought at the end of 2016. For the northeast, Ceara, Paraiba, Pernambuco and Rio Grande do Norte were the states where the reservoirs suffered the most from the extended drought, while Bahia and Piaui were less affected. In the comparison between Castanhao - CE x Cantareira - SP, even with the causes and effects of the droughts being different, the two reservoirs reached levels below the operational minimum, even using the dead volume for supply. Combining the results of the present study with previous works on drought, it has been shown that climate changes have not created more severe meteorological droughts. Even so, situations of extreme droughts and prolonged droughts continue to have a worrying effect on the populations. Finally, the analysis can serve as a preliminary tool to evaluate the impacts of extended droughts in the semi-arid, enabling more efficient actions in the management of water resources.. Keywords: Extended Drought. Semi-arid. Water resources.

\section{INTRODUÇÃO}

A água é um recurso essencial à vida em nosso planeta. Uma das partes do ciclo da água, a precipitação, possui uma natureza bastante aleatória, manifestada pela alternância de períodos chuvosos e períodos secos, trazendo preocupações aos seres humanos desde o início da humanidade. A escassez de chuvas em certas regiões do mundo, portanto, não é um problema atual. As mudanças climáticas ocorridas nos últimos anos ao redor do globo trouxeram a discussão com relação a um possível aumento do número de secas, em especial as prolongadas. Apesar disso, não é de hoje que o problema da ocorrên- cia de grande número de anos consecutivos em que as precipitações são baixas em certos lugares preocupa a população. A própria região do semiárido no Nordeste do Brasil possui relatos de secas prolongadas desde o século XVI. Alguns fatores são preponderantes para a não ocorrência de chuvas: o relevo local da região, que naturalmente impede as massas de ar quente e úmida agir causando precipitações; além de fatores globais, como a variação da temperatura das águas dos oceanos, alterando os padrões de circulação dos ventos e dos deslocamentos de massas de ar, provocando fenômenos que podem intensificar a estiagem. Os longos períodos 
em que as chuvas ocorrem abaixo da média geralmente são os maiores responsáveis pelos prejuízos às populações dessas regiões, como falta de água para consumo humano, para irrigação e para dessedentação animal (MONZONIS et al., 2005; TRENBERTH, 1997). Como esses eventos sempre ocorreram na história da humanidade, as mudanças climáticas não são o fator desencadeador de secas severas ou prolongadas, de forma que a busca para mitigar o problema deve ser constante, visto que períodos de escassez continuarão a ocorrer, prejudicando a sociedade caso soluções não sejam encontradas. Nesse ponto, o gerenciamento dos recursos hídricos de uma região é fundamental.

Os primeiros relatos de seca no Brasil ocorreram na região Nordeste, datando do século XVI, embora seja difícil precisar a quantidade de anos e os impactos dessas secas nesse século e nos dois séculos seguintes, XVII e XVIII, dada a falta de mecanismos de avaliação. Por exemplo, os relatos da época no Ceará estimam que um terço da população do sertão semiárido acabou morrendo no decurso de uma seca ocorrida em 1792 (ALVARGONZALEZ, 1984). A seca iniciada no ano de 1877 e que teve duração até 1879 é considerada um marco para a região Nordeste. Os três anos seguidos de ausência nas precipitações provocaram uma intensa migração da população, conseguindo repercussão nacional e motivando as autoridades das províncias a buscarem soluções para o problema (SOUSA, 2009).

A partir do início do século XX, com a construção dos primeiros açudes e a melhoria nos mecanismos de obtenção de valores das precipitações, o monitoramento das secas pode ser melhor avaliado. Palmer (1965) estabeleceu o Índice de Severidade de Secas de Palmer (ISSP), que define o grau de seca a partir de um balanço hídrico. Tal índice é considerado um parâmetro meteorológico, apesar de ser obtido por meio do cálculo em termos hidrológicos, tendo sido adaptado por vários autores para suas respectivas regiões. Na região Nordeste, um Monitor de Secas é utilizado para monitoramento da severidade de secas, desenvolvido por um grupo de mais de 80 instituições federais e estaduais, destacando-se o apoio do Centro Nacional de Mitigação de Secas (NDMC) da Universidade de Nebraska/ EUA e da Comissão Nacional de Águas do México (CONAGUA). Alguns estudos no Ceará, como o realizado por Alves et al. (1998), consideraram anos de seca extrema no Estado os anos em que os desvios anuais normalizados de precipitação entre os meses de fevereiro a maio (quadra chuvosa) apresentaram valores superiores ou iguais a $-40 \%$ de precipitação.

Um evento de seca pode ser estudado em termos de algumas variáveis: déficit de água com base na precipitação, na vazão, na umidade do solo ou numa combinação dessas variáveis, além de déficits da demanda populacional ou de irrigação em relação à oferta dos recursos hídricos da região. Portanto, o objetivo dos estudos ou das pesquisas em questão pode considerar todos ou se restringir a apenas alguns desses aspectos, dependendo do tipo de seca que quer se analisar, seja ela meteorológica, hidrológica, agrícola ou socioeconômica (FREITAS, 2008).

A situação de cada região com relação aos recursos hídricos disponíveis pode ser classificada pelo nível de disponibilidade de água e pelo nível de utilização. Dessa forma, os países situados no Oriente Médio possuem a situação mais crítica com relação à oferta x uso de água, como Arábia Saudita, Líbia, Jordânia, Israel e Emirados Árabes, entre outros. Algumas regiões nos Estados Unidos, como em Colorado, na Califórnia, também possuem situação de escassez, mas devido principalmente ao alto consumo per capita da região. Brasil e Austrália são classificados como "ricos" em termos de disponibilidade hídrica, mas a má distribuição das precipitações faz com que algumas regiões desses países 
sofram com escassez de água. Por exemplo, em termos médios, o Brasil possui oferta hídrica disponível de $35.732 \mathrm{~m}^{3} / \mathrm{hab} / \mathrm{ano}$, sendo a região Norte responsável por $89 \%$ da disponibilidade hídrica do país; em seguida temos a região Centro-Oeste com $8,4 \%$ da disponibilidade hídrica do país, a região Sul com $1,1 \%$, a região Nordeste com $0,9 \%$ e a região Sudeste com $0,6 \%$. Em termos de população, a distribuição é inversa à disponibilidade hídrica por região: $42 \%$ da população se encontra na região Sudeste, $28 \%$ na região Nordeste, $14 \%$ na região Sul, $8,5 \%$ na região Norte e $7,5 \%$ na região Centro-Oeste. Com isso percebe-se que, apesar de o Brasil possuir em seu território $12 \%$ da água doce do mundo, Sudeste e Nordeste, as duas regiões com maior concentração populacional do país, possuem apenas 1,5\% da disponibilidade hídrica brasileira (REBOUÇAS et al., 2006).

Segundo Rebouças et al. (2006), tanto Ceará como São Paulo, dois Estados muito próximos em termos de disponibilidade hídrica, $2.279 \mathrm{~m}^{3} /$ hab/ano e $2.209 \mathrm{~m}^{3} / \mathrm{hab} / \mathrm{ano}$ respectivamente, são classificados como "suficientes" quanto a essa disponibilidade, tomando-se como referência os valores sugeridos pela Organização das Nações Unidas. Os Estados da região Nordeste encontram-se todos na classificação de "regulares" ou "suficientes" com disponibilidades entre $1000 \mathrm{~m}^{3} / \mathrm{hab} / \mathrm{ano}$ e $3000 \mathrm{~m}^{3} / \mathrm{hab} / \mathrm{ano}$. No entanto, essas disponibilidades hídricas não foram suficientes para atravessar o período de baixas precipitações que se configurou entre os anos de 2012 e 2016. Tal fato, aliado à dificuldade de implementar uma política de uso racional e sustentável de seus recursos hídricos tornou as populações das regiões supracitadas altamente suscetíveis à falta de água (ANA, 2009; DNAEE, 2006; REBOUÇAS, 1973).

No Nordeste, o problema das secas, que já era causa de prejuízos, passou por mais um episódio recente, com a seca de 2012 a 2016 figurando entre os piores períodos de escassez dos últimos 100 anos. Na região Sudeste, o Sistema Cantareira, maior sistema produtor de água da Região Metropolitana de São Paulo, cujo dimensionamento foi realizado com base na seca de 1953, teve seus níveis diminuídos desde o final de 2013 , atingindo seu volume morto devido aos baixos níveis de precipitação do período 2014-2015 (JACOBI et al., 2015; PORTO et al., 2014).

Por fim, diversas regiões no mundo sofrem com as secas prolongadas, como a Califórnia: o período recente de 2012 a 2015 está entre os 5 mais secos dentre os últimos 95 anos. Alguns estudos estatísticos apontaram uma tendência de aquecimento na região e uma tendência de diminuição nos deflúvios, mas, apesar de apontarem que as mudanças climáticas podem ter contribuído para esses eventos extremos, o efeito na realidade é modesto, de forma que os eventos de seca são principalmente resultado da variabilidade na precipitação. Dessa forma, o aquecimento global não pode ser considerado a causa principal de secas prolongadas. (MAO et al., 2015).

Segundo Campos (1999), essas secas prolongadas são as responsáveis pelo colapso dos sistemas de abastecimento hídrico das regiões. Em muitas partes do mundo, segundo Thomson et al. (2005), os modelos climáticos globais (GCMs) não concordam com as mudanças projetadas nas precipitações regionais e na evaporação potencial, enquanto outros estudos apontam previsões de climas mais secos, como McFarlane et al. (2012) citam os GCMs do sudoeste australiano e de regiões em outros países. Qualquer conclusão em relação à causalidade entre mudanças climáticas e diminuição de precipitações ainda é muito precipitada, conforme Winstanley (2005) afirma que o clima em cada região muda naturalmente em todas as escalas de tempo e os dados climáticos do planeta estão disponíveis apenas para os últimos 50 ou 100 anos, o que torna impossível a documentação de alte- 
rações climáticas em intervalos mais longos. Srinivasan et al. (2017) afirmam que nem todas as regiões serão afetadas da mesma forma e que as discussões sobre segurança hídrica devem ir além de análises de alterações climáticas e equilíbrios de oferta e demanda. O problema da falta de água para a população deve continuar sendo uma das maiores preocupações para a sobrevivência e o desenvolvimento humano e a gestão dos recursos hídricos deve ser cada vez mais eficiente, desde o seu monitoramento até a distribuição correta.

Nesse contexto, apresenta-se neste trabalho uma metodologia simplificada de estudo e comparação dos impactos da estiagem entre os anos de 2012 e 2016 no Brasil. O foco principal é o Estado do Ceará, um dos Estados brasileiros que mais sofre com secas, mesmo possuindo ampla estrutura e monitoramento dos seus recursos hídricos. É apresentado ainda um panorama geral dos efeitos em outros Estados do Nordeste e nas Regiões Metropolitanas de São Paulo e de Campinas, regiões que também sofreram bastante os efeitos da insegurança hídrica durante os últimos anos, mas de formas diferenciadas.

\section{METODOLOGIA}

O monitoramento dos recursos hídricos de uma região é fundamental para o gerenciamento e a distribuição da água entre as diversas demandas. No Brasil, desde o ano de 1997, com a instituição do Plano Nacional de Recursos Hídricos, Lei $N^{\circ} 9433$, foram incorporados os princípios e instrumentos mais modernos para a gestão dos recursos hídricos brasileiros. Essa lei, conhecida como “Lei das Águas", institui que a água no Brasil é um bem de domínio público, dotado de valor econômico e um recurso natural limitado; a lei afirma também que o uso prioritário é o abastecimento populacional e animal em situações de escassez; por fim, a gestão dos recursos hídricos deve ser descentralizada, com a participação dos usuários, das comunidades e do Poder Público, proporcionando o uso múltiplo das águas disponíveis. Dessa forma, os órgãos públicos nacionais e estaduais são responsáveis pelo acompanhamento da disponibilidade de água para seus variados usos: em âmbito nacional, o Conselho Nacional de Recursos Hídricos (CNRH) e a Agência Nacional de Águas (ANA); em âmbito regional, a Companhia de Gestão dos Recursos Hídricos (COGERH), a Fundação Cearense de Meteorologia e Recursos Hídricos do Estado do Ceará (FUNCEME) e a Secretaria dos Recursos Hídricos (SRH), no Estado do Ceará, e o Sistema Integrado de Gerenciamento de Recursos Hídricos, no Estado de São Paulo, são alguns exemplos de órgãos que possuem estratégias para monitorar e acompanhar em tempo real os recursos hídricos de seus respectivos Estados (GOMES \& BARBIERI, 2004; RÊGO, 2008).

Para análise desse trabalho foi realizada uma pesquisa em alguns desses órgãos para mostrar a evolução dos recursos hídricos, com foco nas precipitações no século e no período de estudo e nos acúmulos dos reservatórios, nas vazões liberadas para perenização de rios e para perímetros irrigados em termos das diferenças entre a situação inicial e final das regiões no período 2012 - 2016. O foco principal concentrou-se no Estado do Ceará, com levantamento de dados a partir da FUNCEME, da COGERH e da ANA, visto que é um dos Estados mais afetados pelas secas recorrentes e considerado referência em termos de estrutura e monitoramento de seus recursos hídricos. Inicialmente foi apresenta a evolução do Estado do Ceará no decorrer da seca, com a área de estudo delimitada na Figura 1, apresentando também a divisão do Estado em macrorregiões de precipitações homogêneas e a situação de inserção completa do Estado no perímetro delimitado pelo semiárido brasileiro. 


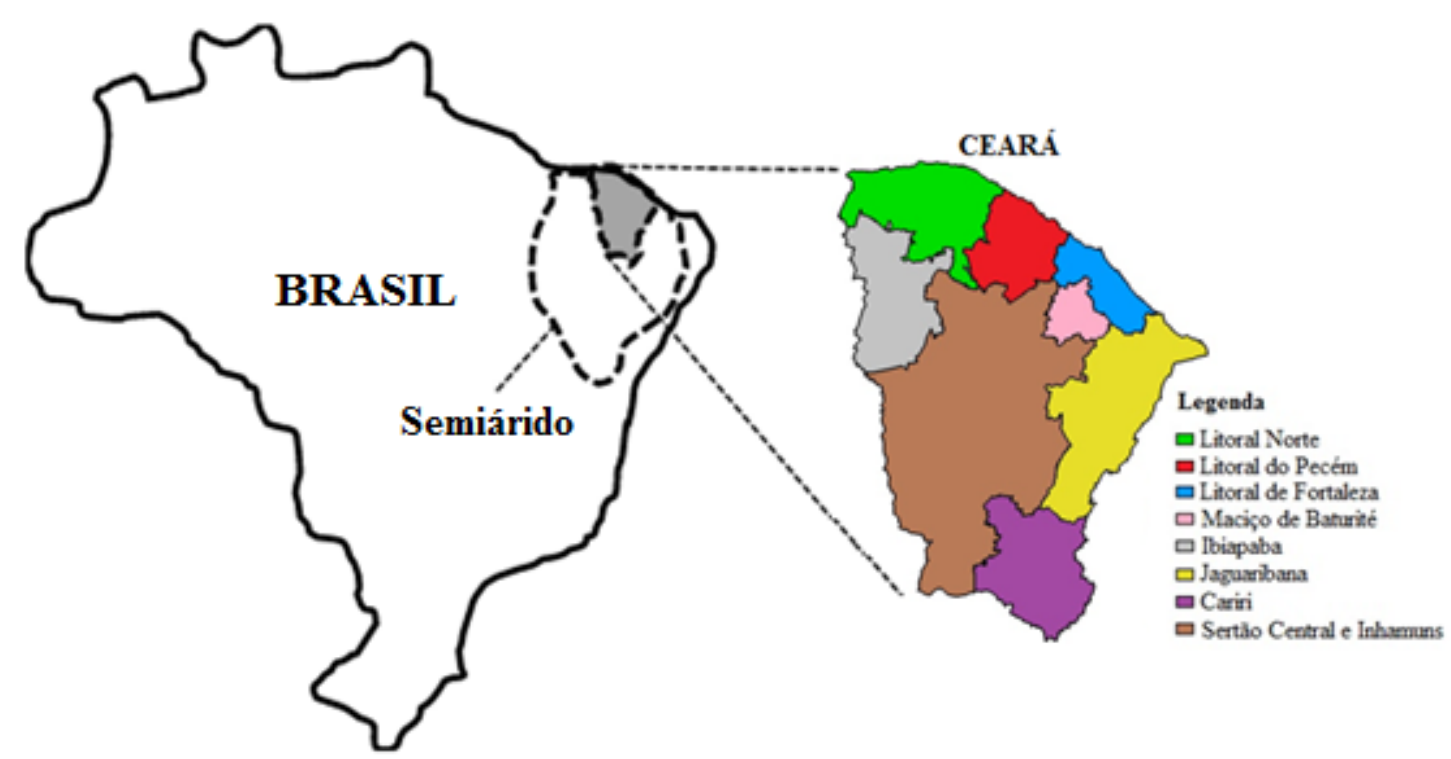

Figura 1 - Mapa de localização do Estado do Ceará, destacando a inserção completa no perímetro do semiárido brasileiro e a divisão em macrorregiões homogêneas de precipitações. (Adaptado de Funceme, 2017)

Os dados de monitoramento foram analisados na seguinte ordem: primeiramente estudou-se a distribuição de precipitações no período citado a partir dos relatórios da Funceme. Como a chuva é a principal fonte de água para o Estado, partiu-se da análise das precipitações médias anuais e das quadras chuvosas do Estado, consideradas entre os meses de fevereiro e maio de cada ano, encontrando-se assim um ranking dos anos com menores índices de precipitação e as diferenças entre total precipitado nas quadras chuvosas em relação à média histórica para os anos de 2012, 2013, 2014, 2015 e 2016.

Após o estudo das precipitações, procurou-se entender a evolução do aporte hídrico do Estado no período, visto que os reservatórios são as principais obras de infraestrutura responsáveis pela manutenção hídrica do Ceará. A partir de dados fornecidos pela COGERH, elaborou-se o gráfico de aporte total a partir de 2004, ano da conclusão do açude Castanhão, que elevou substancialmente a capacidade de armazenamento de água do Estado. Do aporte hídrico, seguiu-se para a análise da evolução do nível dos reservatórios no período, de modo a constatar o decréscimo esperado no percentual acumulado.
A combinação das análises de precipitações e de aporte e nível dos reservatórios foi compilada na situação final da distribuição de água nas bacias hidrográficas do Ceará no início do ano de 2017. Assim buscou-se demonstrar o impacto da seca prolongada e a situação de distribuição espacial da disponibilidade hídrica do Estado em termos de reservas de água.

Como o impacto direto da baixa nas reservas hídricas dos açudes é aplicado na oferta de água, analisou-se, a partir de dados da COGERH, a evolução da vazão liberada pelos sete maiores reservatórios do Estado, a quantidade e a extensão de rios perenizados e a vazão ofertada para os perímetros irrigados do Ceará. Para o impacto populacional, foram analisados os dados da Defesa Civil, com relação à quantidade de municípios que decretaram estado de emergência devido à seca até o final do ano de 2016 e os dados do Exército Brasileiro para a população atendida pela operação carro-pipa.

Com os dados compilados para o Ceará e a análise feita da evolução dos recursos hídricos no período de 2012 a 2016, comparou-se, a partir de dados da 
ANA, a situação dos reservatórios em alguns Estados do Nordeste: Ceará, Bahia, Paraíba, Pernambuco, Piauí e Rio Grande do Norte, além da média geral da região, pelo conceito de reservatório equivalente; analisaram-se também os valores da precipitação total anual Ceará x Nordeste. Um breve estudo também foi realizado com o impacto da escassez de chuvas entre 2012-2016 no Ceará e 2014-2015 em São Paulo, mesmo sabendo que a região Sudeste possui condições climáticas e mecanismos responsáveis pelas precipitações diferentes da região Nordeste, sendo feita análise entre 2011 e 2016 da evolução do percentual de acúmulo do Sistema Cantareira, a partir de dados da SABESP e do Açude Castanhão, a partir de dados da COGERH / Funceme.

\section{RESULTADOS E DISCUSSÃO}

Diante da problemática da seca que atravessa os anos, o Ceará foi um dos que mais investiu em obras de infraestrutura hídrica no último século. Segundo os dados apresentados pela COGERH, durante o século XX, 92 açudes foram construídos, possibilitando armazenar 8,2 bilhões de metros cúbicos de água, implantaram-se 403,74 km de adutoras e $102 \mathrm{~km}$ em eixos de integração (canais e adutoras) para transporte de água entre regiões e instalaram-se 11.028 poços. Já neste início de século XXI, o ritmo de investimento continuou alto, com 26 reservatórios com capacidade total de 8,4 bilhões de metros cúbicos para armazenamento de água, com destaque para o açude Castanhão, que sozinho tem potencial para acumular 6,7 bilhões de metros cúbicos, $825,83 \mathrm{~km}$ de adutoras, $321,31 \mathrm{~km}$ em eixos de integração (canais e adutoras) e 5.148 poços até o ano de 2016, além da principal obra de infraestrutura hídrica do país em andamento, a Transposição do rio São Francisco, com a integração regional ao Cinturão de Águas do Ceará. Apesar de todos os esforços, toda essa estrutura não se apresentou suficiente para superar os efeitos da seca iniciada no ano de 2012.

Os estudos apresentados pela Fundação Cearense de Meteorologia e Recursos Hídricos (Funceme) com relação aos anos com menores precipitações durante a quadra chuvosa de fevereiro a maio no Ceará apontam três dos anos da seca mais recente entre os dez piores em termos de precipitação média observada: 2012, 2013 e 2016, todas entre 300 mm e $400 \mathrm{~mm}$. Nota-se que a década de 1950 possui dois dos quatro piores anos em termos de precipitação, 1958 e 1951, com valores entre 200 mm e 300 mm nesses anos. Dessa forma pode-se concluir que a precipitação anual média nas quadras chuvosas do Ceará em anos de seca severa tem apresentado valores entre $200 \mathrm{~mm}$ e $400 \mathrm{~mm}$. A Figura 2 apresenta a ordem completa dos dez piores anos.

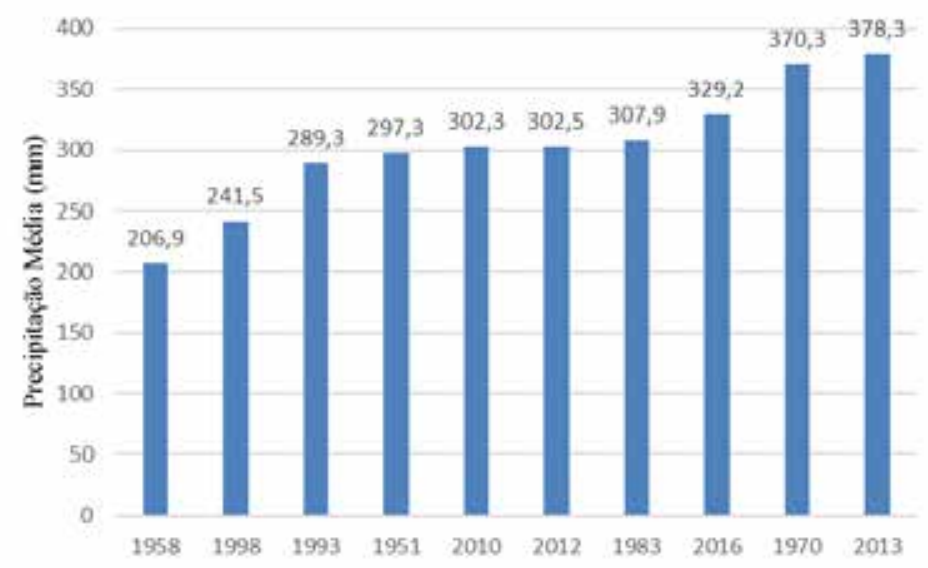

Figura 2 - Os 10 Anos com Menores Precipitações Médias na Quadra Chuvosa do Ceará 
Dos relatórios de análise das precipitações das quadras chuvosas do Ceará, apresentados pela Funceme, apresenta-se na Figura 3 a consolidação das quantidades em $\mathrm{mm}$ precipitadas na quadra chuvosa em cada região homogênea de distribuição de chuvas. Nota-se a variabilidade das chuvas nas diversas regiões do Estado. Na região do Sertão Central e Inhamuns e em Jaguaribana, os resultados da quadra chuvosa apresentaram os menores valores de precipitação, enquanto o Litoral do Pecém e o Litoral de Fortaleza apresentaram os maiores valores de precipitação na quadra chuvosa. A variabilidade espacial das precipitações encontradas seguem o padrão identificado por Neto et al.
(2012), Santos et al. (2014) e Souza et al. (1996). Todas as regiões apresentaram valores de precipitação abaixo da média normal do Estado, de 600,7 $\mathrm{mm}$, conforme boletim da quadra chuvosa atualizado com dados até o ano de 2016 pela Funceme, com exceções somente para Cariri em 2014 e Litoral Norte e Litoral de Fortaleza em 2015. O Ceará como um todo apresentou os seguintes resultados de desvio percentual em relação à média: $-50,7 \%$ no ano de $2012,-37,7 \%$ no ano de $2013,-24,0 \%$ no ano de $2014,-30,6 \%$ no ano de 2015 e $-45,2 \%$ no ano de 2016. Tomando como base os estudos de Alves et al. (1998), os anos de 2012 e 2016 seriam considerados anos de seca extrema.

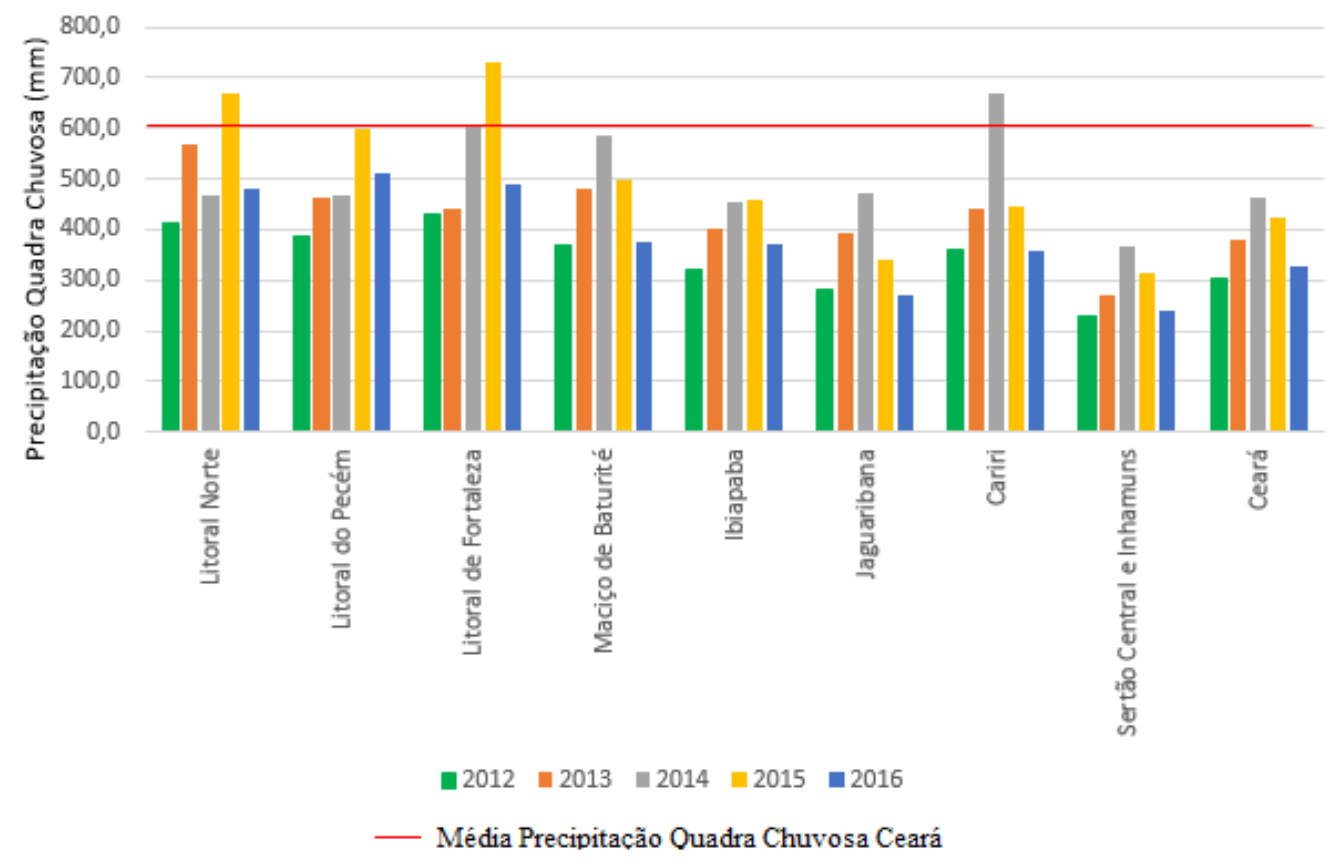

Figura 3 = Evolução do Aporte Hídrico dos Reservatórios Monitorados pela COGERH

Os reservatórios do Estado sofrem impacto direto da escassez de chuvas no Estado, sendo estes os principais responsáveis pelo abastecimento hídrico das regiões do Ceará, com capacidade de armazenamento total de 18,64 bilhões de $\mathrm{m}^{3}$. $\mathrm{O}$ aporte hídrico dos reservatórios monitorados pela COGERH nos últimos 5 anos teve média de 0,91 bilhões de $\mathrm{m}^{3} /$ ano. A Figura 4 apresenta a evolução do aporte desde 2004 a 2016 dos reservatórios monitorados pela COGERH. Na seca mais recente, os aportes encontrados foram de 0,92 bilhões de $\mathrm{m}^{3}$ para o ano de 2012, 0,95 bilhões de $\mathrm{m}^{3}$ para o ano de 2013, 1,16 bilhões de $\mathrm{m}^{3}$ para o ano de 2014, 0,75 biIhões de $\mathrm{m}^{3}$ para o ano de 2015 e 0,77 bilhões de $\mathrm{m}^{3}$ para o ano de 2016. Todos esses valores muito distantes da média de 5 bilhões de $\mathrm{m}^{3}$ anuais do período. 


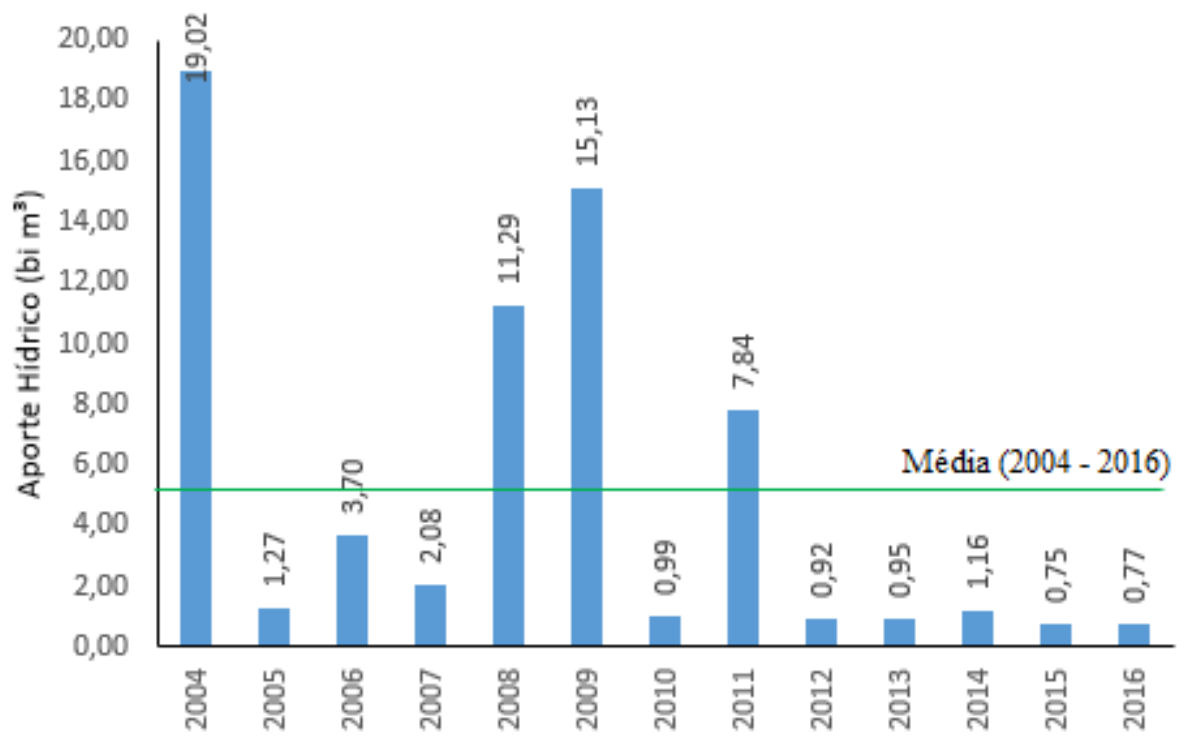

Figura 4 - Evolução do Aporte Hídrico dos Reservatórios Monitorados pela COGERH

Além das precipitações abaixo da média e do baixo aporte dos reservatórios, as grandes taxas de evaporação e as demandas do Estado (atendidas em grande parte pelas reservas dos açudes) também influenciaram na diminuição rápida dos percentuais acumulados e, consequentemente, no aumento dos efeitos da estiagem no Ceará. Dessa forma os reservatórios, além de não receberem recarga adequada, perdiam grande parte de sua ca- pacidade por evaporação e para atendimento das demandas. A Figura 5 apresenta a evolução do percentual armazenado pelos reservatórios do Estado desde 2011, ano em que o Estado estava com relativa segurança hídrica. Os dados fornecidos pela COGERH mostram que os níveis dos reservatórios caíram de 85,15\% para 6,90\% do final de 2011 até o final do ano de 2016, ou seja, uma redução de armazenamento de 15,9 para 1,3 bilhões de $\mathrm{m}^{3}$.

\section{$85,15 \%$}

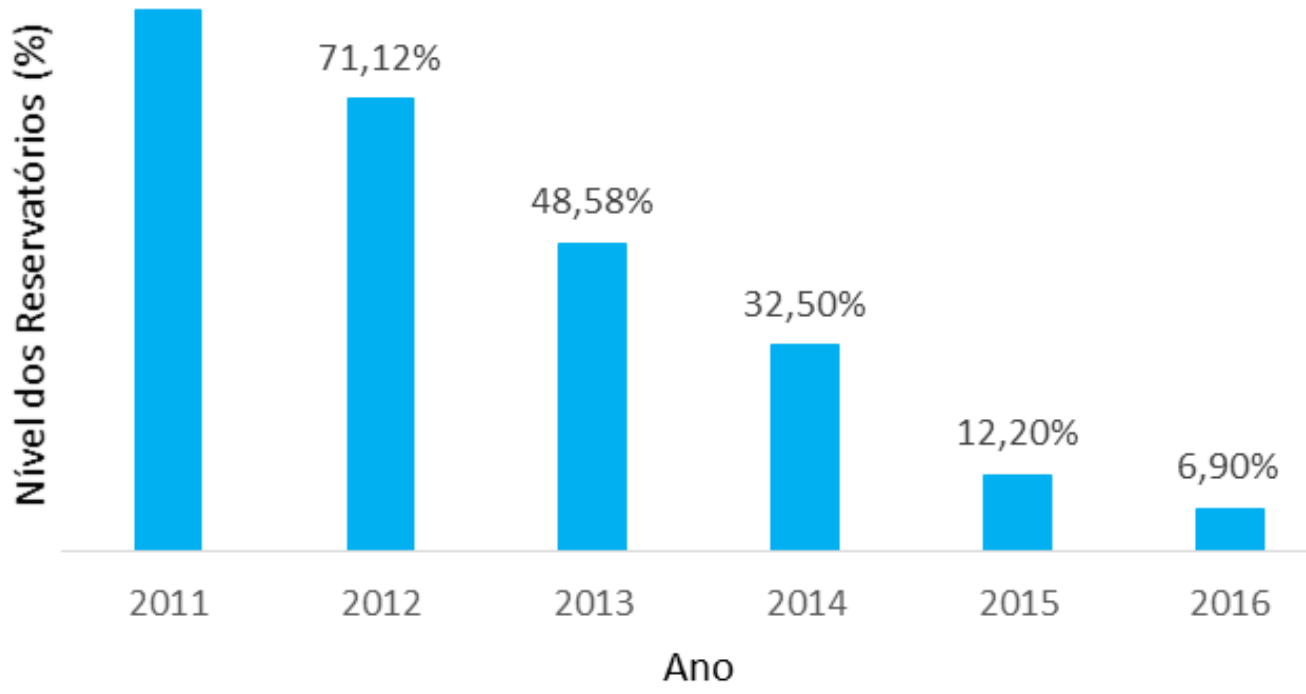

Figura 5 - Evolução do Nível Percentual de Acúmulo ao Final de cada Ano dos Açudes Monitorados pela COGERH 
A distribuição espacial do percentual armazenado nos reservatórios do Ceará no início do ano de 2017 é apresentada na Figura 6, a partir do mapa de bacias hidrográficas do Estado. Observa-se que 136 açudes dos 153 monitorados pela CO-
GERH apresentavam volumes abaixo de $30 \%$. Nota-se que a região central apresentava um volume de acúmulo praticamente nulo, enquanto a zona do litoral apresentava volume acumulado correspondente a $25 \%$ da capacidade.

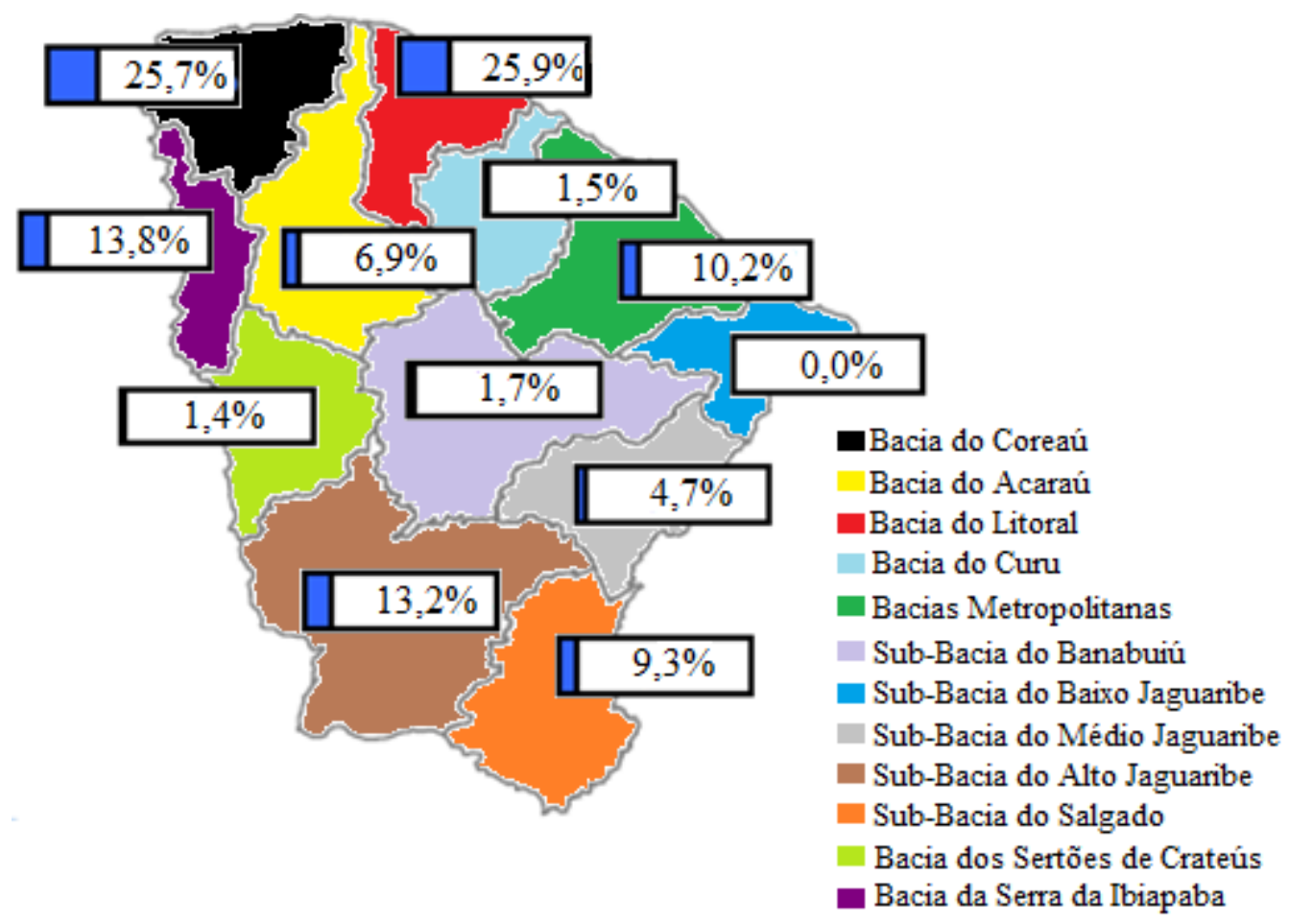

Figura 6 - Distribuição Espacial do Acúmulo de Água nos Reservatórios por Bacia Hidrográfica do Estado do Ceará no Início de 2017

Os sete maiores reservatórios, responsáveis pelo armazenamento de $65 \%$ da capacidade total do Estado, o equivalente a 12 bilhões de $\mathrm{m}^{3}$ de água, tiveram uma redução drástica na vazão liberada. De 2012 a 2016, a vazão liberada caiu de 1,91 bilhões de $\mathrm{m}^{3} /$ ano $\left(60,7 \mathrm{~m}^{3} / \mathrm{s}\right)$ para 0,50 bilhões de $\mathrm{m}^{3} /$ ano $\left(15,81 \mathrm{~m}^{3} / \mathrm{s}\right)$, uma redução de $74 \%$ na vazão liberada. Os dados fornecidos pela COGERH são apresentados na Figura 7. Nota-se que nos dois primeiros anos há um aumento na vazão anual fornecida pelos reservatórios, visto que a demanda do Estado passa a ser atendida principalmente pelos mesmos, dada as baixas precipitações que ocorriam. Nos três últimos anos, a vazão liberada começa a cair por motivos de gestão e de ações de racionamento de água, que ocorreram devido aos riscos de esgotamento do sistema. 


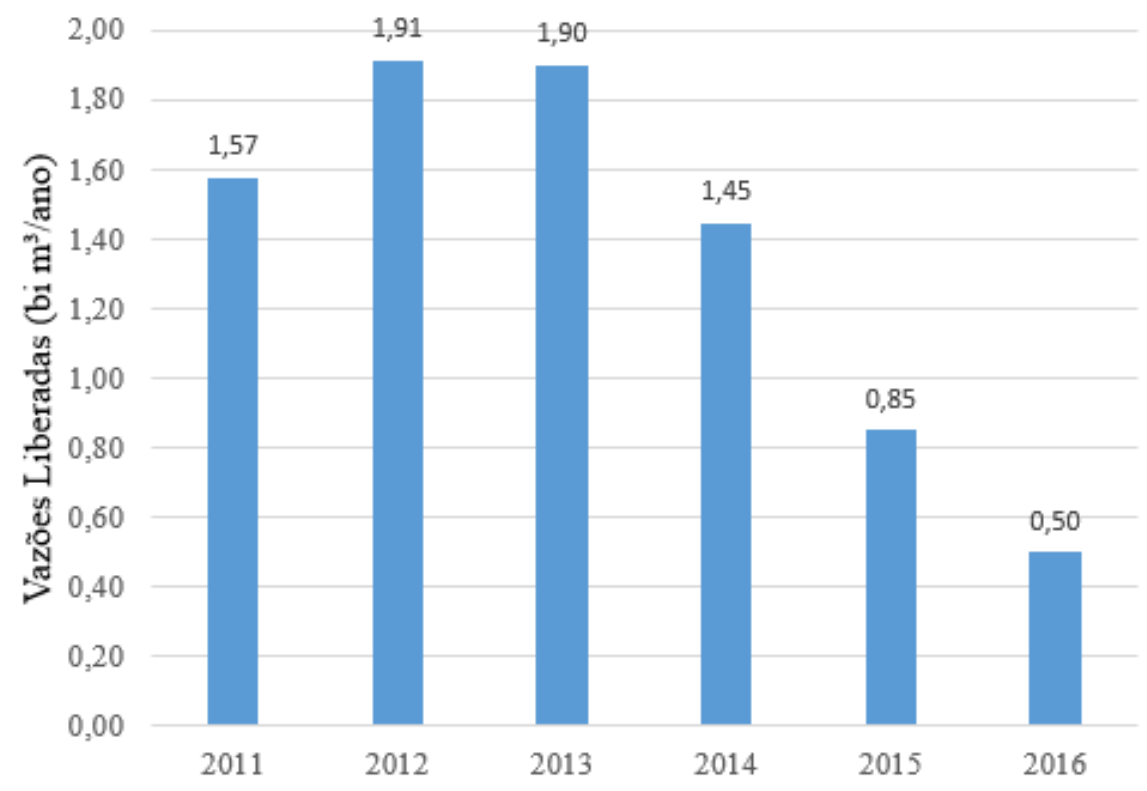

Figura 7 - Evolução da Vazão Anual Liberada pelos 7 Maiores Açudes do Estado do Ceará

A diminuição da vazão liberada pelos açudes teve impacto direto na quantidade de rios perenizados no Estado do Ceará. Entre os anos de 2012 e 2016 houve uma queda acentuada na quantidade de rios perenizados, de 89 para 28 , com a extensão de perenização reduzida de $2479 \mathrm{~km}$ de rios pere- nizados em 2012 para $557 \mathrm{~km}$ de rios perenizados em 2016, representando uma diminuição de 78\%. Os dados fornecidos pela COGERH são apresentados na Tabela 1, que mostra a evolução da quantidade de rios e a distância perenizada entre 2011 e 2016.

Tabela 1 - Evolução dos Rios e da Extensão Perenizada no Ceará.

\begin{tabular}{|c|c|c|c|c|c|c|}
\hline Situação Hídrica & 2011 & $\mathbf{2 0 1 2}$ & $\mathbf{2 0 1 3}$ & $\mathbf{2 0 1 4}$ & $\mathbf{2 0 1 5}$ & 2016 \\
\hline $\mathrm{N}^{\circ}$ de Açudes Monitorados & 138 & 142 & 147 & 150 & 154 & 153 \\
\hline $\mathrm{N}^{\circ}$ de Rios Perenizados & 88 & 89 & 71 & 52 & 29 & 28 \\
\hline Extensão da Perenização (km) & 2535 & 2479 & 2166 & 1460 & 680 & 557 \\
\hline Redução da Extensão (\%) & - & $-2 \%$ & $-15 \%$ & $-42 \%$ & $-73 \%$ & $-78 \%$ \\
\hline
\end{tabular}

Juntando-se os resultados encontrados para a diminuição dos níveis dos reservatórios, da distribuição de água nas bacias hidrográficas e na vazão liberada pelos açudes, atesta-se o defendido por Campos (1999), visto que os reservatórios de grande porte foram alternativas para alívio de secas interanuais, suportando baixas precipitações durante cinco anos seguidos, com três deles entre os dez piores em termos de precipitação histórica no Estado e dois considerados anos de extrema seca meteorológica segundo Alves et al. (1998).
Os reservatórios, porém, não podem ser a única alternativa de oferta de água para a mitigação da seca no semiárido. A transposição de águas de outras bacias, como do Rio São Francisco, já em curso, e do Rio Tocantins, a dessalinização da água do mar e das águas subterrâneas, a diminuição das perdas nas redes de abastecimento humano, o aumento da eficiência na irrigação e o reúso de água são alternativas que devem ser estudadas e melhor desenvolvidas na região, com a gestão dos recursos hídricos sendo feita de forma integrada. 
A agricultura, sendo responsável por $62 \%$ da demanda de água do Estado do Ceará, é a principal responsável tanto pelo sustento da população do campo como pelas altas taxas de exportação de produtos irrigados no Estado. O efeito direto da estiagem entre 2012 e 2016 é mostrado na Figura 8, que apresenta a evolução da vazão liberada para os perímetros irrigados do Ceará nesses últimos cinco anos. Os dados fornecidos pela COGERH mostram que as vazões liberadas para os oito maiores perímetros irrigados do Estado caiu de 0,72 bilhões de $\mathrm{m}^{3} / \mathrm{ano}\left(22,95 \mathrm{~m}^{3} / \mathrm{s}\right)$ para 0,11 bilhões de $\mathrm{m}^{3} / \mathrm{ano}\left(3,58 \mathrm{~m}^{3} / \mathrm{s}\right)$, de 2012 a 2016, representando uma diminuição de $84,4 \%$ no volume de água disponibilizado para irrigação, de tal forma que desde 2015 a vazão liberada para seis dos oito principais perímetros irrigados do Estado é nula ou praticamente nula. Em situações de secas prolongadas, é natural a diminuição da oferta para a agricultura em termos de gestão dos recursos hídricos, mas segundo Coelho et al. (2005) o aumento da eficiência da irrigação a partir do manejo adequado e da otimização da tecnologia é fundamental para melhorar o cenário do sistema durante as secas. Segundo Saraiva et al. (2012), o Ceará possui quase $85 \%$ dos seus sistemas de irrigação do tipo menos eficiente, pelos métodos de aspersão e de superfície, que possuem rendimentos entre $50 \%$ e $75 \%$.

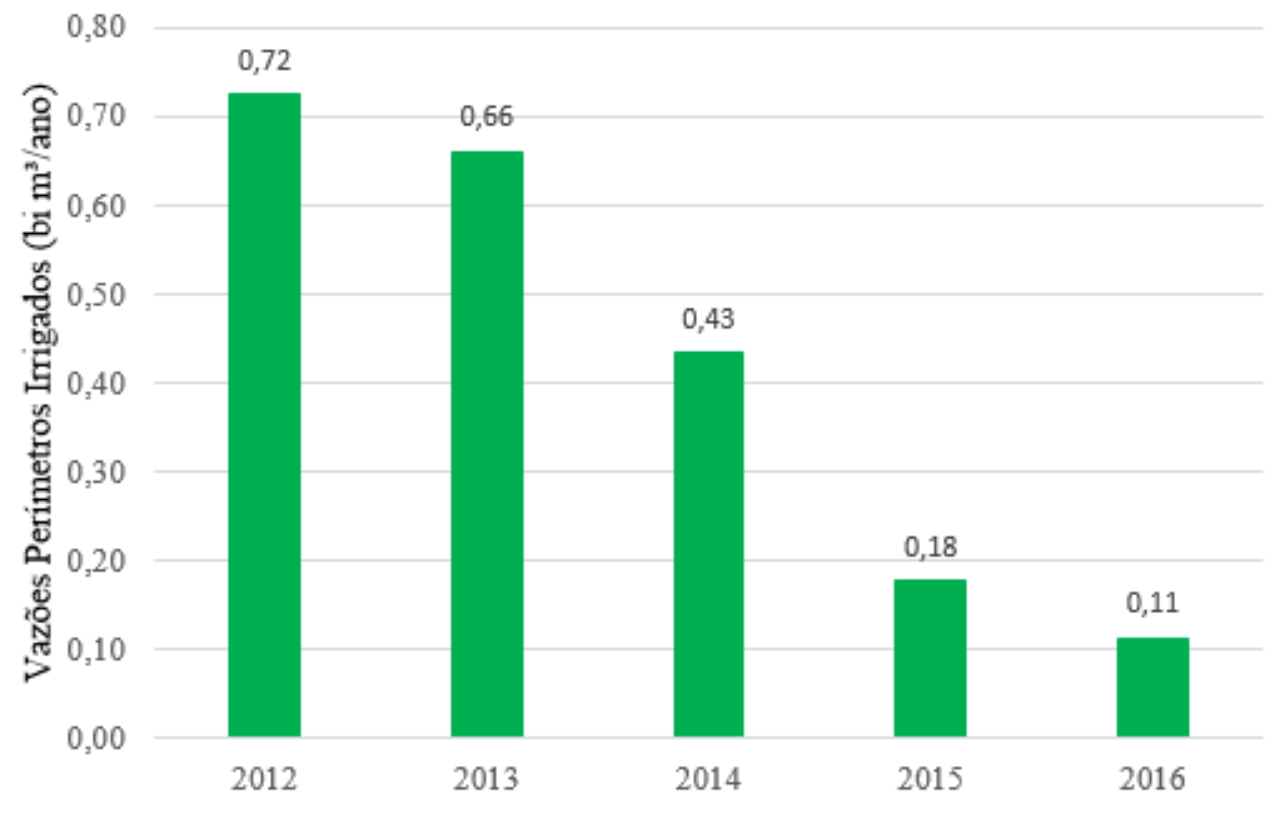

Figura 8 - Evolução da Vazão Anual Liberada para Perímetros Irrigados no Ceará

O consumo populacional também apresentou situação crítica no período de 2012 a 2016. A Defesa Civil apresentou no início de 2017 uma atualização para os municípios que se encontravam em estado de emergência devido à estiagem. Verifica-se que 137 municípios possuíam situação reconhecida, enquanto apenas 47 apresentavam normalidade em relação à falta de água. A solução mais utilizada para os casos em que os municípios decretam estado de emergência devido à seca foi a transferência de água de uma região para outra em regime de urgência por meio de adutoras de montagem rápida ou por meio de carros-pipa. Os dados levantados pelo exército brasileiro, da evolução da quantidade de pessoas atendidas pela operação carro-pipa de 2012 a 2016, mostram 
que esse número subiu de 648.162 para 957.464 pessoas atendidas. Esse número indica que $20 \%$ da população do interior do Estado estava sendo atendida pelos carros-pipa do exército no início do ano de 2017. Tal número mostra que as secas continuam a impactar um alto percentual da população, como relatado por Alvargonzalez (1984), onde, na seca de $1792,33 \%$ da população foi a óbito devido aos efeitos da severa seca. A Tabela 2 apresenta a evolução da quantidade de pessoas atendidas, os pontos de abastecimento e a quantidade de veículos disponibilizada pelo exército entre os anos de 2012 e 2016. Vale ressaltar que o exército brasileiro atua em distritos e comunidades rurais, enquanto a defesa civil estadual apenas em sedes municipais.

Tabela 2 - Evolução da População Atendida pela Operação Carro-Pipa do Exército Brasileiro no Estado do Ceará

\begin{tabular}{|c|c|c|c|c|c|c|}
\hline Situação & $\mathbf{2 0 1 2}$ & $\mathbf{2 0 1 3}$ & $\mathbf{2 0 1 4}$ & $\mathbf{2 0 1 5}$ & $\mathbf{2 0 1 6}$ & $\mathbf{2 0 1 6}$ \\
\hline População Atendida & 648.162 & 810.877 & 858.636 & 874.147 & 957.464 & 153 \\
\hline Pontos de Abastecimento & 7.744 & 9.682 & 11.290 & 14.510 & 15.997 & 28 \\
\hline Quantidade de Veículos & 726 & 1.010 & 1.166 & 1.550 & 1.708 & 557 \\
\hline
\end{tabular}

A situação do Estado apresentou-se extremamente preocupante no início do ano de 2017, com os recursos hídricos praticamente esgotados e os prognósticos de precipitações nada animadores. Tais fatos ligam o alerta para uma gestão cada vez mais eficiente dos recursos hídricos, para as diminuições das perdas nos sistemas de abastecimento da população e da irrigação e para a procura de novas fontes de abastecimento, visto que a demanda de água tende a aumentar com o passar do tempo, seja pelo aumento populacional, seja pelo desenvolvimento tecnológico da região. $\mathrm{O}$ exemplo do Estado do Ceará serve de alerta para outras regiões que sofrem ou venham a sofrer com secas prolongadas.

Comparando-se os Estados do Nordeste pode-se perceber um panorama médio dos impactos da seca prolongada nos recursos hídricos da região. A Figura 9 apresenta uma comparação entre o reservatório equivalente da região como um todo e de alguns dos seus respectivos Estados. Dos dados apresentados pela Agência Nacional de Águas (ANA), a região Nordeste apresentou uma diminuição nas águas armazenadas no reservatório equivalente de 44,9\% para 17,3\% entre 2012 e 2016 . Conforme Marengo et al. (2016), era esperado que a seca não impactasse os reservatórios dos Estados de maneira igual. 0 Estado do Ceará foi o que apresentou a queda mais acentuada, saindo de um percentual de acúmulo de
53,4\% em 2012 para 7,7\% em 2016. Paraíba, Pernambuco e Rio Grande do Norte foram bastante afetados pelo período de estiagem, enquanto Bahia e Piauí não sofreram impactos tão grandes. Tal resultado corresponde aos Estados mais impactados dentro do Polígono das Secas conforme Duque (1980). O conceito de reservatório equivalente considera apenas os reservatórios com capacidade de acúmulo acima de $10 \mathrm{hm}^{3}$. Os dados de precipitação fornecidos pela ANA, apresentados na Figura 10, mostram a evolução de precipitação média anual comparando-se Nordeste e Ceará, entre os anos de 2007 e 2016. Apesar desse resultado, vale lembrar que outras variáveis impactam diferentemente os níveis dos reservatórios para cada Estado, por exemplo as taxas de evaporação e as políticas de gerenciamento das águas.

O total anual precipitado no Estado do Ceará foi sempre menor que a média encontrada para a região Nordeste. Conclui-se também que sete dos últimos dez anos apresentaram chuvas anuais abaixo da média histórica no Estado, com apenas os anos de 2008, 2009 e 2011 apresentando chuvas acima dessa média anual histórica. A média considerada no presente artigo foi de $874,9 \mathrm{~mm}$, conforme estudos realizados por Barreto et al. (2012) a partir dos dados de 342 postos pluviométricos de 1911 a 1990, assim apresentada na Figura 10. 


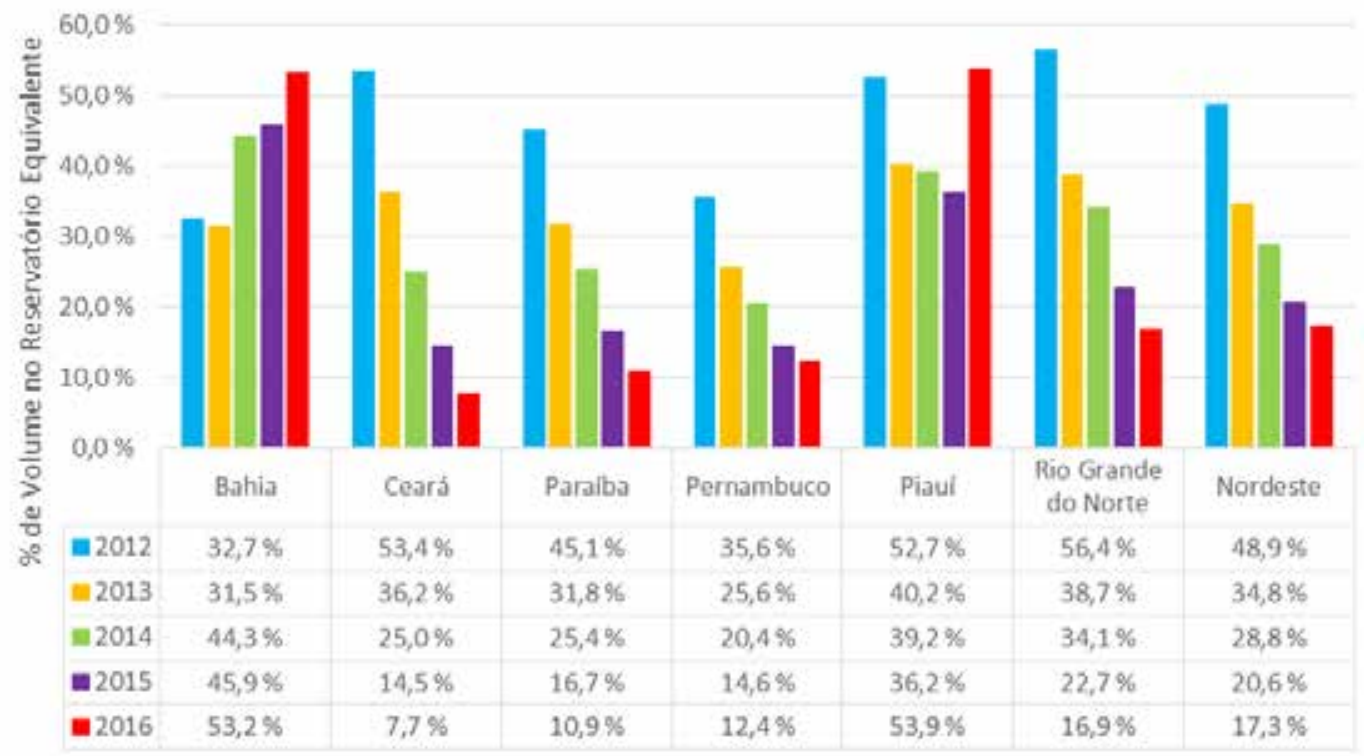

Figura 9 - Evolução do Reservatório Equivalente na Região Nordeste

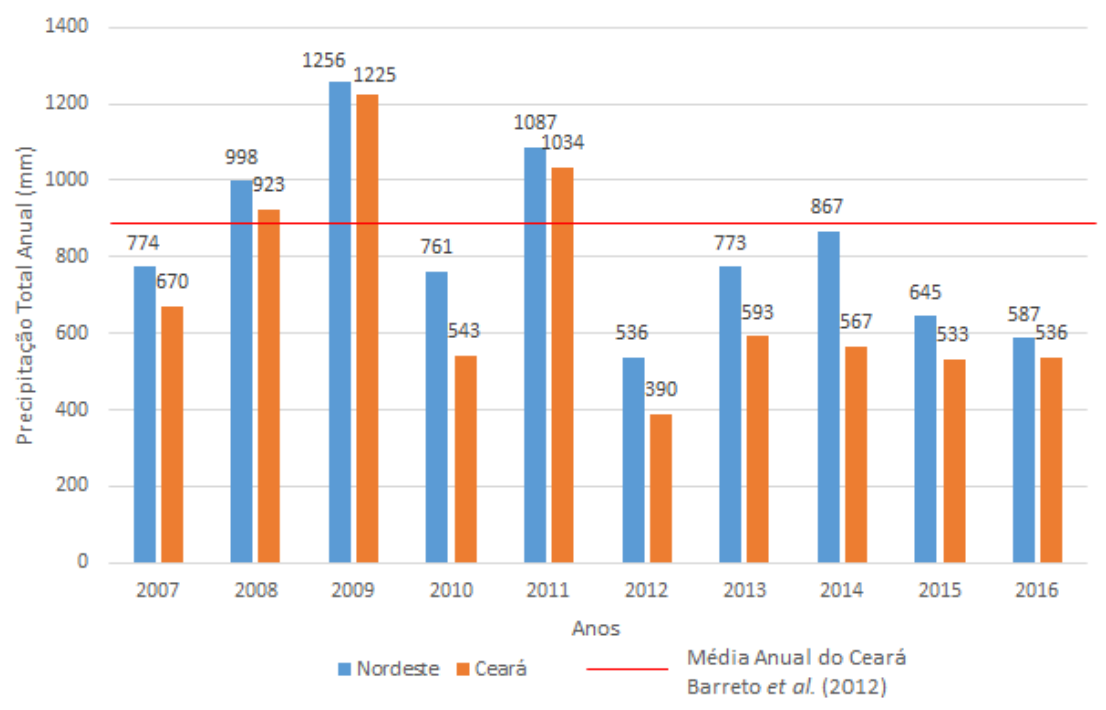

Figura 10 - Evolução da Precipitação Anual Nordeste x Ceará

Enquanto o Estado do Ceará vivia uma das piores secas prolongadas de sua história, a Região Metropolitana de São Paulo atravessava no período 20142015 sua pior crise hídrica dos últimos 60 anos. Segundo Coutinho et al. (2015), o principal impacto da seca foi sentido no Sistema Cantareira, chegando a registrar um percentual de acúmulo abaixo do seu volume útil e utilizando-se dos volumes mortos do sistema a partir de maio de 2014. O Sistema Cantareira foi concluído na década de $1980 \mathrm{com}$ a função de abastecer 8,8 milhões de pessoas na
Região Metropolitana de São Paulo a partir da captação e do tratamento de água, com produção de $33 \mathrm{~m}^{3} / \mathrm{s}$, sendo composto por seis barragens interligadas e uma estação de bombeamento para transpor a Serra da Cantareira. Caso ocorram eventos que levem a crises hídricas severas, pode-se fazer o uso da chamada reserva técnica do Sistema Cantareira, conhecido como "volume morto", localizado abaixo das estruturas operacionais dos reservatórios e sendo acessível apenas por bombeamento. Tal "volume morto" tem potencial para adicionar 
cerca de 480 bilhões de litros de água no sistema (NETO, 2016; SORIANO et al., 2016).

De forma a ilustrar os fenômenos ocorridos nos dois Estados, a Figura 11 apresenta a evolução do percentual de acúmulo do sistema Cantareira e do açude Castanhão, ao final de cada ano, entre os anos de 2011 e 2016. Nota-se que entre os anos de 2013 e 2014 o acúmulo do Sistema Cantareira decaiu de $45,2 \%$ no final de 2013 para 5,3\% no final de 2014, recuperando-se a partir de então para $58,3 \%$ no final de 2016 , com esses valores já considerando os volumes das reservas técnicas utilizadas. Para o açude Castanhão, o nível de acúmulo só diminuiu durante o período, decaindo de $73,7 \%$ no final do ano de 2011 para 5,1\% no final de 2016.

Diferentemente do Ceará, a estiagem em São Paulo ocorreu em um período de tempo menor, concentrada durante dois anos. Segundo Marengo et al. (2015), o mês de janeiro de 2014 foi considerado o mais seco dos últimos 42 anos na região do Sistema Cantareira, com uma precipitação medida em $87,9 \mathrm{~mm}$, quando a média histórica, considerada entre 1983-2014, era de $268 \mathrm{~mm}$. As bacias que contribuíam para os reservatórios também apresentaram afluentes inferiores à média, com a vazão medida em 2014 de 11,3 $\mathrm{m}^{3} / \mathrm{s}$, com a média entre 1930 e 2013 atingindo o valor de 44,1 m³.s.

O Cantareira e o Castanhão são reservatórios plurianuais, ou seja, são dimensionados para suportar alguns anos de baixas precipitações. A capacidade do Açude Castanhão é de 6,7 bilhões de $\mathrm{m}^{3}$, com 250 milhões de $\mathrm{m}^{3}$ de volume morto, e a do Sistema Cantareira é de 1,462 bilhões de $\mathrm{m}^{3}$, sendo 480 milhões de $\mathrm{m}^{3}$ referentes às três reservas técnicas. Em São Paulo, o Sistema Cantareira utilizou duas das três reservas técnicas dimensionadas, a primeira em maio de 2014, adicionando 182,5 milhões de $\mathrm{m}^{3}$ de água ao sistema, ou $18,5 \%$ sobre o volume total e a segunda em novembro de 2014, adicionando $105 \mathrm{mi}-$ lhões de $\mathrm{m}^{3}$ de água, ou 10,6\% sobre o volume total. Além do acionamento das reservas técnicas, neces- sitando de bombeamento e aumentando os custos com energia, foram realizadas obras emergenciais de captação e incentivos à redução de consumo da população por meio de bônus para quem reduziu voluntariamente seu consumo e ônus para quem aumentou o mesmo, em relação à média do período prévio à crise. No Ceará, a Região Metropolitana de Fortaleza, capital do Estado, sentiu a crise hídrica por meio da tarifa de contingência na cobrança da água, o que buscou incentivar a redução do consumo, embora não tenha ocorrido racionamento, diferentemente da população do interior, em especial no sertão central, que sofreu de forma mais acentuada com a escassez de água.

Os impactos das secas recentes não foram exclusividade das regiões brasileiras. Na Califórnia, nos Estados Unidos, o período 2012 a 2014 está entre os cinco piores da região, segundo Mao et al. (2015). Na Austrália, na região Sudeste, entre os anos de 2001 e 2009 ocorreu a chamada seca milenar, considerada a pior seca já registrada na história do país, segundo van Dijk et al. (2013), causando prejuízos extremos aos recursos hídricos e consequentemente à população. Os resultados obtidos para o Brasil, considerando Ceará, Nordeste e São Paulo, aqui descritos, e os já obtidos em outros países, corroboram que os eventos de seca ocorrem sistematicamente em todo o mundo, com variabilidade em termos de severidade em todas as épocas. Os prognósticos de piora do quadro de secas devido às mudanças climáticas não devem ser uma preocupação maior em relação às que naturalmente deve-se ter com relação à segurança hídrica, até pelo fato de a confiabilidade nos dados de temperatura e de precipitações ter uma história bastante recente em comparação à idade do nosso planeta. Variações climáticas já ocorreram e continuarão a ocorrer, de forma que o real problema deve estar focado na gestão integrada dos nossos recursos hídricos, principalmente com o aumento da eficiência dos sistemas e a diminuição das perdas, de forma que se possa atender um número maior de usos e usuários de acordo com seus reais crescimentos. 


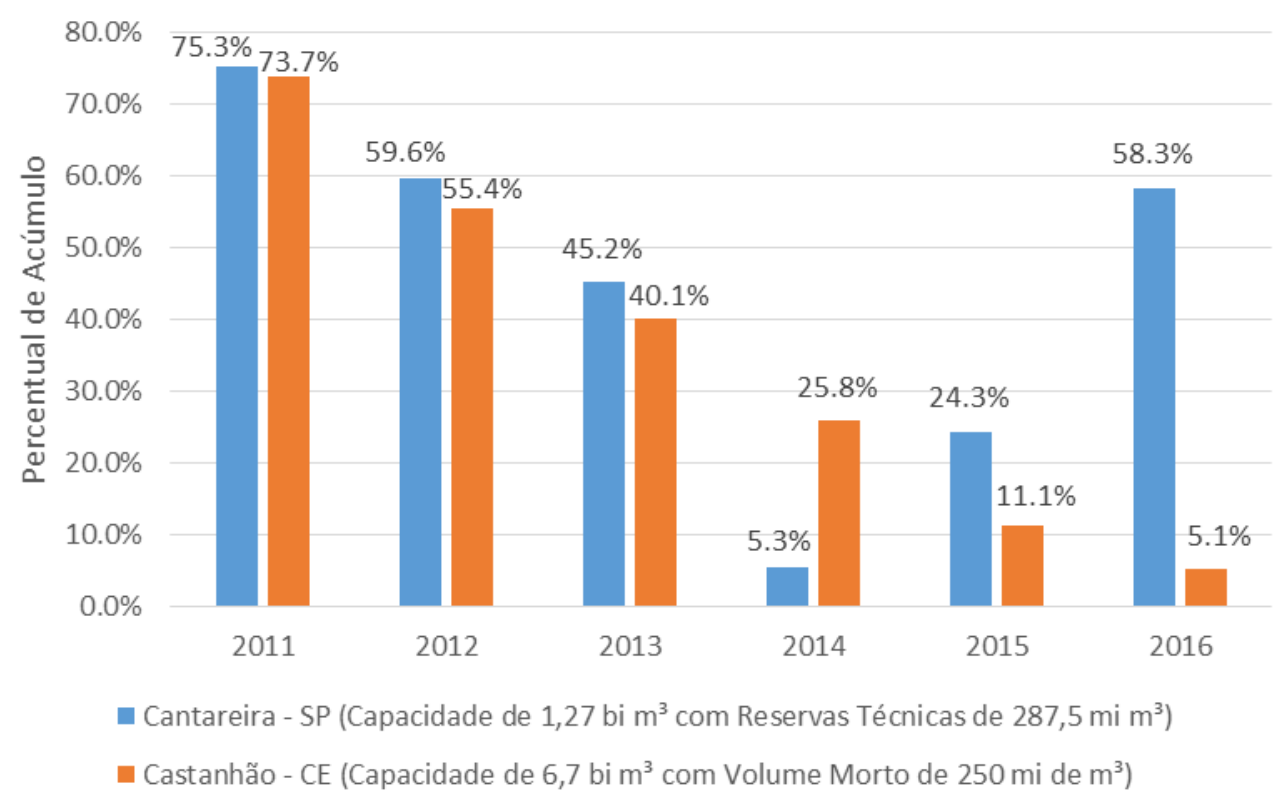

Figura 11 - Comparação dos Percentuais Acumulados entre 2012 e 2016 (Sistema Cantareira São Paulo x Açude Castanhão - CE)

\section{CONCLUSÕES}

A pesquisa apresentou uma breve análise dos efeitos de uma seca prolongada em uma região semiárida, no caso para o Estado do Ceará, durante cinco anos ininterruptos. Além disso, pôde-se comparar os efeitos com outros Estados situados na mesma região climática e com essa região como um todo; também ilustrou-se os efeitos das crises hídricas nos níveis dos principais reservatórios responsáveis pelo abastecimento entre o Ceará e São Paulo, Estado pertencente a outra região climática. Os principais resultados do estudo são apresentados a seguir:

- Em termos de precipitações, o Estado do Ceará apresentou todos os cinco anos do período 2012 - 2016 com chuvas abaixo da média durante sua quadra chuvosa. Os desvios percentuais em relação à média histórica do Estado são compilados a seguir: $-50,7 \%$ no ano de $2012,-37,7 \%$ no ano de $2013,-24,0 \%$ no ano de $2014,-30,6 \%$ no ano de 2015 e $-45,2 \%$ no ano de 2016.

- Durante o período 2012 - 2016, três anos estão entre os dez piores em termos de precipitação na quadra chuvosa no Estado: 2012, 2013 e 2016, com valores entre $300 \mathrm{~mm}$ e $400 \mathrm{~mm}$. Apesar de não serem os anos com menores níveis de chuva registrados na história, estando os menores na faixa entre $200 \mathrm{~mm}$ e $300 \mathrm{~mm}$, percebe-se a grande diferença em relação à média histórica, essa em torno de $600 \mathrm{~mm}$ na quadra chuvosa cearense.

- De 2004 a 2011, a média de aporte dos reservatórios monitorados pela COGERH era de 7,67 bilhões de metros cúbicos por ano. No período de 2012 a 2016, a média de aporte dos reservatórios foi de 0,91 bilhão de metros cúbicos por ano. 0 volume armazenado nesses açudes caiu de $85,15 \%$ para $6,90 \%$, representando uma queda de $78,25 \%$ nos níveis volumétricos dos reservatórios.

- Apesar do baixo aporte e da grande queda no nível dos açudes, o percentual acumulado por bacia hidrográfica foi bastante variável ao final de 2016: as bacias da região central, como a do sertão de Crateús, do médio e do baixo Jaguaribe apresentaram percentuais praticamente nulos. Já as bacias litorâneas, como a do Coreaú e a do Litoral apresentaram percentuais próximos a $25 \%$. Isso 
evidencia a variabilidade da oferta de água dentro do próprio Estado.

- Com a diminuição dos níveis de acumulação dos reservatórios do Estado, o número de rios perenizados caiu de 88 para 28 no período. A extensão desses rios perenizados caiu de $2535 \mathrm{~km}$ para $557 \mathrm{~km}$, representando uma redução de $78 \%$. A vazão ofertada pelos sete maiores reservatórios decresceu de $60,70 \mathrm{~m}^{3} / \mathrm{s}$ para $15,81 \mathrm{~m}^{3} / \mathrm{s}$, uma redução de $74 \%$.

- Os efeitos diretos na irrigação e no consumo populacional, as duas maiores demandas do Estado, foram sentidos da seguinte forma: a vazão ofertada para os principais perímetros irrigados caiu de $22,95 \mathrm{~m}^{3} / \mathrm{s}$ para $3,58 \mathrm{~m}^{3} / \mathrm{s}$, uma diminuição de 84,4\%; no final do ano de 2016, 137 dos 184 municípios do Estado declararam situação de emergência populacional devido à seca.

- Todas essas reduções são esperadas em termos dos conceitos de gestão dos recursos hídricos em situações de seca prolongada. A conclusão final é que investimentos em infraestrutura hídrica, aumento de eficiência dos sistemas de abastecimento e redução de consumo devem continuar sendo feitos para garantia da segurança hídrica, visto que a projeção é de aumento das demandas devido ao crescimento populacional e tecnológico.

- Na comparação com a região Nordeste, concluiu-se que o Ceará apresentou o maior decréscimo de percentual acumulado (-45,7\%) em termos de reservatório equivalente. Paraíba, Pernambuco e Rio Grande do Norte apresentam reduções parecidas às do Ceará, -34,2\%, -23,2\% e $-39,5 \%$ respectivamente, sofrendo os efeitos da seca prolongada de forma similar. Bahia e Piauí não apresentaram o mesmo perfil de decréscimo do reservatório equivalente, sofrendo de forma menos intensa os efeitos dessa estiagem recente. Vale destacar que as precipitações não são as únicas a explicarem os efeitos sentidos pelos níveis dos reservatórios, mas a evaporação local e as diferentes políticas de gerenciamento de cada Estado contribuem para isso.

- Na comparação entre os principais sistemas de abastecimento com o Estado de São Paulo, verificou-se que tanto o Sistema Cantareira quanto o Açude Castanhão apresentaram diminuições no percentual acumulado em valores semelhantes, porém em durações diferentes: o Cantareira decresceu seu percentual para atingir o volume morto em apenas dois anos, 2014-2015, enquanto o Castanhão atingiu percentuais de acúmulo muito próximos somente no período 2015-2016, ou seja, nos dois últimos anos da seca prolongada de cinco anos.

Por fim, cabe salientar que problemas relacionados a baixas precipitações voltarão a ocorrer, dada a natureza cíclica dos eventos meteorológicos, e a tendência é que as crises sejam maiores devido ao crescimento populacional, caso novas alternativas não sejam encontradas. Dessa forma, uma gestão cada vez mais eficiente dos recursos hídricos será fundamental para atravessarmos as futuras crises.

\section{REFERÊNCIAS}

ALVARGONZALEZ, R. 0 desenvolvimento do Nordeste árido. Ministério do Interior / DNOCS: Fortaleza, 539 p., 1984.

ALVES, J. M. B., SOUZA, E. B., REPELLI, C. A. Principais Secas Ocorridas Neste Século no Estado do Ceará: Uma Avaliação Pluviométrica. Anais do X Congresso Brasileiro de Meteorologia e VIII Congresso da FLISMET. Brasília, DF, 1998.

ANA. Agência Nacional de Águas. Disponível em: <http://www2. ana.gov.br/Paginas/default.aspx>. Acesso em: 16 jan. 2017.

ANA - Agência Nacional de Águas. Fatos e Tendências: Água. Brasília, 2009.

ANA - Agência Nacional de Águas. Monitor de Secas do Nordeste do Brasil. Disponível em: < http://monitordesecas.ana. gov.br/>. Acesso em: 15 fev. 2017.

BARRETO, H.B.F.; SANTOS, W.O.; CRUZ, C.M. Análise da distribuição da precipitação pluviométrica média anual no Estado do Ceará. Revista Verde de Agroecologia e Desenvolvimento Sustentável. v. 7, n. 2, p. 122 - 128, 2012. 
CAMPOS, J.N.B. A água e a vida: textos e contextos / José Nilson B. Campos. - Fortaleza: ABC Fortaleza, 142 p., 1999.

COELHO, E.F., COELHO FILHO, M.A., OLIVEIRA, S.L. Agricultura Irrigada: Eficiência de Irrigação e de Uso de Água. Revista Bahia Agrícola. v. 7, n. 1, set. 2005.

COGERH. Companhia de Gestão dos Recursos Hídricos. Disponível em: <http://www.hidro.ce.gov.br/>. Acesso em: 7 jan. 2017.

COUTINHO, R.M.; KRAENKEL, R.A.; PRADO, P.I. Catastrophic Regime Shift in Water Reservoirs and São Paulo Water Supply Crisis. Journal PLOS ONE, 10 (9), 2015.

DNAEE - Departamento Nacional de Águas e Energia Elétrica. Plano nacional de recursos hídricos. Brasília, 2006.

DUQUE, J.G. Solo e água no polígono das secas. 5. ed. Mossoró: Fundação Guimarães Duque, 1980.

FREITAS, M.A.S. O Fenômeno das Secas no Nordeste do Brasil: Uma Abordagem Conceitual. Anais do IX Simpósio de Recursos Hídricos do Nordeste. Bahia, 2008.

FUNCEME. Fundação Cearense de Meteorologia e Recursos Hídricos. Disponível em: <http://www.funceme.br/>. Acesso em: 10 set. 2016

GOMES, J.L.; BARBIERI, J.C. Gerenciamento de recursos hídricos no Brasil e no Estado de São Paulo: um novo modelo de política pública. Cadernos EBAPE.BR, v. II, n. 3, p. 1-21, 2004.

JACOBI, P.R. CIBIM; J. LEÃO, R.S. Crise hídrica na Macrometrópole Paulista e respostas da sociedade civil. Estudos avançados. São Paulo.v. 29, n. 84, 2015.

LEI DAS ÁGUAS. Lei № 9.433, de 8 de Janeiro de 1997: Da Política Nacional de Recursos Hídricos. Presidência da República, Casa Civil, Subchefia para Assuntos Jurídicos. 1997. Disponível em: <https://www.planalto.gov.br/ccivil_03/leis/19433.htm>. Acesso em: 25 nov. 2016

MAO, Y.; NIJSSEN, B.; LETTENMAIER, D.P. Is climate change implicated in the 2013 -2014 California drought? A hydrologic perspective. Geophysical Research Letters. n. 42, p. $2805-2813$, 2015 .

MARENGO, J.A.; CUNHA, A.P.; ALVES, L.M. A seca de 2012-15 no semiárido do Nordeste do Brasil no contexto histórico. Revista Climanálise - Edição Comemorativa de 30 anos, 2016.

MARENGO, J.A.; NOBRE, C.A.; SELUCHI, M.E.; CUARTAS, A.; ALVES, L.M.; MENDIONDO, E.M.; OBREGÓN, G.; SAMPAIO, G. A seca e a crise hídrica de 2014-2015 em São Paulo. Revista USP. n. 106, p. 31-44, 2015.

MCFARLANE, D.; STONE, R.; MERTENS, S.; THOMAS, J.; SILBERSTEIN, R.; ALI, R; HODGSON, G. Climate change impacts on water yields and demands in south-western Australia. Journal of Hydrology. 475, p. 488-498, 2012.
MONZONIS, M.P.; SOLERA, A.; FERRER, J.; ESTRELA, T.; ARQQUIOLA, J.P. A Review of Water Scarcity and Drought Indexes in Water Resources Planning and Management. Journal of Hydrology. 527, p. 482 - 493, 2015.

NETO, J. C. C. A crise hídrica no Estado de São Paulo. Geousp Espaço e Tempo (Online), v. 19, n. 3, p. 479-484, 2016.

NETO, S.J.S.; BARRETO, H.B.F.; SANTOS, W.O.; AMARAL JUNIOR, V.P.; MAIA, P.M.; FREIRE, F.G.C. Variabilidade Espacial Pluviométrica do Estado do Ceará para o Mês de Fevereiro. Anais do IV Workshop Internacional de Inovações Tecnológicas na Irrigação. Ceará, 2012.

PALMER, W.C. Meteorological Drought. Office of Climatology. Weather Bureau, Research Paper n. 45, 58p. Washington, 1965.

PORTO, R.L.; PORTO, M.F.A; PALERMO, M. A ressurreição do volume morto do Sistema Cantareira na Quaresma. Revista DAE. n. 197, p. $18-25,2014$.

REBOUÇAS, A.C., BRAGA, B., TUNDISI, J.G. Águas Doces no Brasil: Capital Ecológico, Uso e Conservação. $3^{\circ}$ ed. São Paulo: Escrituras, $2006.748 \mathrm{p}$.

REBOUÇAS, A. C. Le probléme de l'eau dans la zone semi-aride du Brésil. Evaluation des ressources, orientation pour la mise en valeur: Strasbourg, 1973. Thèse (doctorat D'État), Université de Strasbourg, France, 1973. 285 p.

RÊGO, T.C.C.C. Proposta Metodológica para Gestão de Secas: o Caso da Bacia do Alto Jaguaribe, Ceará. Tese (Doutorado em Recursos Hídricos), Universidade Federal do Ceará, Fortaleza, 2008. $193 \mathrm{f}$.

SABESP. Companhia de Saneamento Básico do Estado de São Paulo. Disponível em: <https://www.nivelaguasaopaulo.com/ cantareira>. Acesso em: 15 mai. 2017.

SANTOS, D.C.; MEDEIROS, R.M.; BRITO, J.I.B. Padrão Espacial Pluviométrico no Estado do Ceará. I Workshop Internacional Sobre Água no Semiárido Brasileiro, Paraíba, 2014.

SARAIVA, K.R., SOUZA, F. de, SANTOS, E.M. dos, LIMA, A.D. Cenário da Irrigação no Nordeste do Brasil Segundo o Censo Agropecuário 2005-2006. IV WINOTEC - Workshop Internacional de Inovações Tecnológicas na Irrigação. Fortaleza : CE, 2012.

SORIANO, E.; LONDE, L.R.; GREGORIO, L.D.; COUTINHO, M.P.; SANTOS, L.B.L. Crise hídrica em São Paulo sob o ponto de vista dos desastres. Revista Ambiente \& Sociedade. v. XIX, n. 41, p. $21-42,2016$.

SOUSA, J.W.F. Política e Seca no Ceará. Um Projeto de Desenvolvimento para o Norte (1869 - 1905). Tese (Doutorado em História Econômica), Universidade de São Paulo, São Paulo, 2009. $265 \mathrm{f}$.

SOUZA, E.B.; ALVES, J.M.B.; REPELLI, C.A. A Variabilidade Espacial da Precipitação sobre o Estado do Ceará. Anais do IX Congresso Brasileiro de Meteorologia. Campos do Jordão, 1996. 


\section{SRH. Secretaria dos Recursos Hídricos - Governo do Estado do}

Ceará. Disponível em: <http://www.srh.ce.gov.br/>. Acesso em: 11 jan. 2017.

SRINIVASAN, V.; KONAR, M.; SIVAPALAN, M. A dynamic framework for water security. Water Security Journal. v. 1, p. $12-20$, 2017.

THOMSON, A.M.; BROWN, R.A.; ROSENBERG, N.J.; IZAURRALDE, R.C.; SRINIVASAN, R. Climate change impacts for the conterminous USA: An integrated assessment. Part 4: Water resources. Climatic Change. 69, p. $67-88,2005$.
TRENBERTH, K.E. The Definition of El Niño. Bulletin of the American Meteorological Society. v. 78, n. 12, p. 2771-2777, 1997.

VAN DIJK, A.IJ.M; BECK, H.E.; CROSBIE, R.S.; JEU, R.A.M.; LIU, Y.Y.; PODGER, G.M.; TIMBAL, B.; VINEY, N.R. The Millennium Drought in southeast Australia (2001-2009): Natural and human causes and implications for water resources, ecosystems, economy, and society. Water Resources Research - AGU Journal. v. 29, i. 2, p. $1040-1057,2013$.

WINSTANLEY, D. Climate Aspects of Water Supply Planning. World Water and Environmental Resources Congress 2005. Anchorage, Alaska, United States. May 15-19, 2005. 